\title{
Use of systematic screening to increase the provision of reproductive health services in Bolivia
}

\author{
James R. Foreit \\ Population Council \\ Ricardo Vernon \\ Population Council \\ Patricia Riveros Hamel \\ Population Council
}

Follow this and additional works at: https://knowledgecommons.popcouncil.org/departments_sbsr-rh

Part of the Demography, Population, and Ecology Commons, Health Services Research Commons, and the International Public Health Commons

How does access to this work benefit you? Let us know!

\section{Recommended Citation}

Foreit, James R., Ricardo Vernon, and Patricia Riveros Hamel. 2005. "Use of systematic screening to increase the provision of reproductive health services in Bolivia," FRONTIERS Final Report. Washington, DC: Population Council. 


\section{Use of Systematic Screening to Increase the Provision of Reproductive Health Services in Bolivia}

Frontiers in Reproductive Health Program

James R. Foreit

Ricardo Vernon

Patricia Riveros Hamel

August 2005

This study was funded by the U.S. AGENCY FOR INTERNATIONAL DEVELOPMENT (USAID) under the terms of Cooperative Agreement number HRN-A-00-98-00012-00 and Population Council In-house Project No. 8000 13069. The opinions expressed herein are those of the authors and do not necessarily reflect the views of USAID. 


\section{ABSTRACT}

The study objective was to determine if the use of a checklist that screened for unmet services needs could increase the number of services per visit provided to clients using rural Bolivian health facilities. The study included 3,448 clients visiting six service delivery points during the eighteen-week study period. Measurement included changes in services per visit before and after the introduction of the intervention, and a comparison of services received at screened and nonscreened visits. In the nine weeks following the introduction of the intervention, nine percent more services per client visit were provided than in the nine-week period preceding the intervention $(\mathrm{p}<.001)$. Provider compliance was an important constraint. Less than half of visits were screened, but screened visits resulted in twenty-five percent more services per visit than non-screened visits $(\mathrm{p}<.001)$. To the degree that provider compliance can be secured, systematic screening of clients appears to be an effective method for reducing unmet health service needs. The findings of this study replicate those of other studies conducted in Africa, Asia, and Latin America. The Bolivia Ministry of Health plans to scale-up the intervention. 


\section{INTRODUCTION}

As a consequence of the 1994 Cairo International Conference on Population and Development (ICPD) Program of Action, integration of reproductive health services has become a priority for many developing country health programs. FRONTIERS tested the effectiveness of systematic screening in four countries as a technique for improving the integration of services at the provider level, which is defined as the proactive offer of additional services during client visits (Foreit, Hardee, and Agarwal 2002). In systematic screening, providers use a checklist to screen clients for unmet service needs. The identified services are then offered to the client at the same visit, a subsequent visit, or a referral if the desired service cannot be provided at the same facility. The ultimate goal of systematic screening is to reduce unmet health service needs among program clients.

The study was conducted at the request of the Bolivia Ministry of Health (MOH) to address the problem of low health services utilization in rural areas. One of the most important performance indicators used by the $\mathrm{MOH}$ is the number of services provided per unit of population by health areas. The Ministry considers systematic screening as a possible solution to low services provision because, unlike more expensive outreach programs, it targets clients already visiting health facilities.

Rural areas in Bolivia are generally characterized by poor access and few possibilities for conducting outreach to increase utilization (e.g., health workers have insufficient transportation, $\mathrm{MOH}$ norms discourage health workers from leaving their posts to conduct information and education activities). The $\mathrm{MOH}$ selected Chuquisaca, one of the poorest departments in Bolivia, as the site of the test. The department is mainly inhabited by Quechua speakers, one of the most deprived groups in the country. The department also has among the poorest reproductive health indicators in Bolivia, including a total fertility rate of 6.0 and an unmet need for contraception of 40 percent.

The MOH reasoned that if systematic screening could be successful in an inadequately performing health network, it could be successful in most health networks. Consequently, the municipality of Zudañez, the poorest in the department, was selected as the location of the study. The municipality has no telephone services and is characterized by a widely dispersed population. Sucre, the nearest city, is over 100 kilometers from Zudañez over dirt roads that are mostly impassable during the five-month rainy season. The municipal health network consists of five small health posts and one larger health center offering inpatient as well as outpatient services. The network is consistently one of the lowest performing in the country, and staff is considered among the least motivated in the entire health system.

\section{METHODOLOGY}

Participants and design: The objective of the study was to determine if systematic screening would increase the number of services provided per visit in the Zudáñez health network. Women 15-49 years of age and children ages 0-4 years participated in the study. All were clients in the five health posts and the health center. The center has four doctors, a dentist, a pharmacist, a lab technician, two professional nurses, two auxiliary nurses, and an administrator. An auxiliary nurse staffs each health post. Both the posts and the center provide reproductive and child health 
services, including pre- and post-natal care, contraception, maternal tetanus vaccination, and the full range of childhood immunizations, micronutrients, growth monitoring, and simple curative care. In addition to the services offered by posts, the health center provides diagnosis and treatment of sexually transmitted infections, attends normal deliveries, and offers general medicine, dentistry, and minor surgery. Except for curative care and growth monitoring, facilities are underutilized, and clients usually do not have to wait in line for services.

A before and after design compared the number of services received per client visit for nine weeks before and nine weeks after the introduction of screening. Although the design fails to control for factors such as secular trends, seasonality, or random fluctuations in the number of clients, the dependent variable is much more stable than the number of visits alone, justifying the use of the relatively low-power design, especially when time and budget constraints are taken into consideration. The possibility of a confounding event was reduced by conducting the experiment over a relatively short period of time, and the intervention was scheduled when the $\mathrm{MOH}$ had no health promotional campaigns planned.

The length of observation was based on the decision to obtain a minimum of 600 observations in each facility (300 before and 300 after the intervention). The experiment took place between May and October 2004. Planned comparisons included the mean number of services provided per visit before and after the intervention, and the number of services per visit provided to screened and non-screened clients, post intervention. Because services per visit are not normally distributed, a non-parametric statistic, the Mann-Whitney U, was used to test differences between groups.

Intervention: The intervention consisted of three instruments: (1) a form (see Appendix) used for screening clients; (2) a poster for the walls of the facilities that informed clients of the availability of screening; and, (3) a client brochure explaining more about the procedure. Fourteen persons including all five health post providers and all 11 health center staff were trained for four hours in systematic screening.

Dependent variable: The dependent variable was services received per eligible client visit. Changes in seven services including curative, gynecology, dentistry, nutrition and growth monitoring, family planning, prenatal care, and vaccination were measured. The impact of screening on referrals was not tested. Providers felt that these appointments were virtually impossible for clients to keep, given the long distances, poor infrastructure, and poverty of the area. To determine the acceptability and feasibility of screening, the study also examined the number of clients screened and reasons for not screening.

Procedure: All women and children meeting the inclusion criteria were to be screened. At the health center, for all services except dentistry, an auxiliary nurse met and screened the clients entering the facility. If an unmet need for an additional service was detected, the client was given a coupon listing the desired additional service(s) to take to the appropriate providers. The coupons were also used to determine the number of services actually provided during the visit. The dentist screened his own patients and issued a coupon if additional services were requested. Health posts are staffed with a single provider who was responsible for all screening and service provision. 
Data on visits, screening, and services was collected from routine service statistics forms. The form is a matrix that lists the name of each client followed by the primary reason for the visit. Columns record whether the visit was the first or subsequent visit for the problem, and each service received during the visit. The staff member filling out the form penciled in the letter " $D$ " alongside the names of screened clients. Service statistics forms record the general category but not the specific type of service received. For instance, contraceptive services are recorded as family planning regardless of the method, and all inpatient services except births are recorded as either "medicine" or "surgery."

Intervention monitoring: A project coordinator was to visit facilities approximately every two weeks. She was to collect and transcribe information, check algorithm use, solve problems, and make sure posters were displayed, brochures distributed, and coupons available.

\section{RESULTS}

Implementation of the intervention: Two of the five participating health posts failed to implement the intervention and were dropped from the study. In one post, the auxiliary nurse went on maternity leave during the post-intervention period. In the other, the auxiliary nurse was injured in an auto accident and was away from the post for most of the experiment. Since neither provider could be replaced, local authorities closed the posts.

In the remaining facilities, approximately 45 percent of visits during the post-intervention period were screened, including 45 percent in the health center and 43 percent in posts. Clients of less utilized services were more likely to be screened than clients of more heavily utilized services. In services with 200 or more visits during the post-intervention period, 37 percent of clients were screened compared to 71 percent in services with fewer than 200 visits.

Supervision proved difficult due to travel and communication problems. Also, the coordinator was unable to demand compliance from providers, and frequent retraining and exhortation produced no improvement in screening frequency. Providers who gave reasons for not screening cited stock-outs of coupons, frequent staff meetings resulting in provider absence, and lack of time for screening clients in crowded services.

Equivalence of groups: During the nine-week pre-intervention period, a total of 1,454 clients visited the facilities compared to 1,984 during the nine-week post intervention period. The health center served 1,009 clients before and 1,517 after, a 50 percent increase. Health posts served 390 clients before the intervention and 515 after, a 32 percent increase. The differences are mostly attributable to increases in curative visits (which increased from 699 to 867) and nutrition and growth monitoring visits (which increased from 522 to 768). Reasons for clinic visits were similar during both periods. Before the intervention, curative care, nutrition and growth monitoring were the most popular services. Curative care accounted for 43 percent of visits, followed by 28 percent for nutrition and growth monitoring. Post-intervention, the most common reasons for visits remained unchanged, 37 percent came for curative care and 30 percent for nutrition and growth monitoring. Group characteristics were similar in both periods. Prior to the intervention, 74 percent of clients were seen in the health center, compared to 75 percent post- 
intervention. About 59 percent of pre-intervention clients were children under five compared to 62 percent post-intervention.

Services per visit pre- and post-intervention: The mean number of services per visit during the nine weeks prior to the intervention was 1.1. During the nine weeks following, the number of services per visit was 1.2, a difference of 9 percent $(p<.001)$. The mean number of services received before and after the intervention was analyzed by the reason given for making the visit. Analysis was limited to the seven broad service categories having at least 30 visits during each period. As shown in Table 1, the mean number of services per visit was greater in the postintervention period in six of seven cases, and the difference was statistically reliable in three of the six cases.

TABLE 1. Mean Number of Services Received by Reason for Original Visit, Pre- and Post-Intervention

\begin{tabular}{|c|c|c|c|c|c|}
\hline \multirow[t]{2}{*}{ Original reason for visit } & \multicolumn{2}{|c|}{ Number of visits } & \multicolumn{2}{|c|}{$\begin{array}{c}\text { Mean number of services } \\
\text { per visit }\end{array}$} & \multirow{2}{*}{$\begin{array}{l}\text { Percent } \\
\text { Change }\end{array}$} \\
\hline & $\begin{array}{c}\text { Pre- } \\
\text { intervention }\end{array}$ & $\begin{array}{c}\text { Post- } \\
\text { intervention }\end{array}$ & $\begin{array}{c}\text { Pre- } \\
\text { intervention }\end{array}$ & $\begin{array}{c}\text { Post- } \\
\text { intervention }\end{array}$ & \\
\hline Curative & 1011 & 1284 & 1.19 & 1.20 & 1 \\
\hline Gynecology & 31 & 59 & 1.52 & 1.61 & 6 \\
\hline Nutrition/Growth monitoring & 573 & 902 & 1.09 & 1.15 & $6^{\star \star}$ \\
\hline Dentistry & 98 & 306 & 1.07 & 1.18 & $10^{*}$ \\
\hline Family planning & 120 & 175 & 1.14 & 1.39 & $22^{\star \star}$ \\
\hline Prenatal & 118 & 128 & 1.08 & 1.13 & 5 \\
\hline Vaccination & 65 & 126 & 1.10 & 1.10 & 0 \\
\hline
\end{tabular}

On average, women visiting for curative care or gynecology (also usually a curative service) and children coming for vaccination received no more services post-intervention than preintervention, probably because of low levels of screening. In contrast, the more frequently screened family planning and dentistry clients received more services per visit post-intervention.

Services per visit among screened and non-screened clients: Since more than half of all visits made during the post-intervention period were not screened, we also compared services per visit for screened and non-screened visits. This analysis presents a picture of the effectiveness of the intervention when actually implemented. Non-screened clients had a mean of 1.2 services per visit compared to 1.5 for screened visits, a difference of 25 percent $(\mathrm{p}<.001)$.

The project also compared differences between screened and non-screened visits for two priority services, family planning and prenatal care. The 1,551 services delivered during non-screened visits included 33 (2\%) family planning services. In comparison, the 1,127 services delivered during screened visits included $143(10 \%)$ family planning services. Prenatal services showed the second greatest difference between screened and non-screened visits, two percent versus seven percent, respectively. Overall, 89 percent of all detected service needs resulted in delivered services, including 86 percent of detected family planning service needs and 90 percent of 
prenatal service needs. Detection of need for dental care resulted in the lowest rate of service provision, 67 percent.

\section{DISSEMINATION AND UTILIZATION}

One-day results presentations were held in Zudañez for health network staff, in Sucre, the capital of the department of Chuquisaca, for departmental health authorities, and in La Paz for nationallevel health staff, donors, and NGOs. The Ministry of Health expressed a desire to scale-up the systematic screening intervention, beginning with the remaining municipalities in Chuquisaca.

\section{DISCUSSION}

The introduction of systematic screening resulted in an overall nine percent increase in health services per client visit in one of the most remote and poorest performing health networks in Bolivia. The effectiveness of the intervention was further demonstrated by the fact that screened visits resulted in 25 percent more services than visits where screening did not occur. About 89 percent of detected needs resulted in the delivery of services.

The finding that systematic screening reduces unmet health service needs is robust. The results of this study replicate those of other, similar studies, in Guatemala and Mexico (Vernon and Foreit 1999), Peru (León et al. 1998), India (Das et al. 2005), and Senegal (Sanogo et al. 2005). The effectiveness of the technique is complemented by its simplicity and low cost — systematic screening requires only a few hours of training and, in this study, the screening instrument was a single laminated sheet usable for a long period of time, and a pencil mark on a service statistics form was used to monitor compliance with screening.

The intervention in this study consisted of three elements: the screening instrument, posters, and brochures. The contribution of the posters and brochures to the success of the intervention should be tested. Posters and brochures add to the expense of systematic screening, and potentially create logistics problems since brochures need to be replenished, and damaged posters replaced. Moreover, interventions limited to the use of screening forms have been successful in Guatemala, Mexico, India, and Senegal.

Lack of provider compliance was the most important factor limiting the effectiveness of systematic screening. Major compliance problems appear to have been lack of provider motivation and lack of time for screening clients in crowded services. Similar compliance problems were encountered in a systematic screening experiment in Honduras, as well as in tests of other job aids and in the implementation of new provider procedures (Vernon et al. 2005). Provider compliance with new norms and activities is essential for directed service delivery change to occur. Ensuring compliance is an important managerial function in health programs, but this function is a rarely studied topic in operations research on reproductive health. The detection of provider compliance problems and tests of interventions to overcome those problems should become a focus of operations research. Since lack of provider time for screening in heavily utilized services has been identified as a major compliance problem, the 
development of instruments screening for only one or two priority health needs might produce a large increase in the number of visits screened. Finally, because of fewer structural compliance problems, systematic screening may be especially suited to underutilized facilities in rural areas where unmet services delivery needs are highest, and provider productivity lowest. 


\section{REFERENCES}

Das, N. P. et al. 2005. "Systematic screening to integrate reproductive health services in India," FRONTIERS Final Report, Washington, DC: Population Council.

Foreit, Karen G. Fleischman, Karen Hardee, and Kokila Agarwal. 2002. "When does it make sense to consider integrating STI and HIV services with family planning services?” International Family Planning Perspectives 28(2): 105-107.

León, Federico et al. 1998. "Increasing use of reproductive health services in a Peruvian clinic," in Family Planning Operations Research: A Book of Readings, eds. James R. Foreit and Tomas Frejka. New York: Population Council, pp. 239-245.

Sanogo, Diouratié et al. 2005. "Using systematic screening to increase integration of reproductive health services delivery in Senegal,” FRONTIERS Final Report, Washington, DC: Population Council.

Vernon, Ricardo and James Foreit. 1999. "How to help clients obtain more preventative reproductive health care,” International Family Planning Perspectives 25(4).

Vernon, Ricardo et al. 2005. "Systematic screening as a strategy to increase services integration and revenues in Honduras,” FRONTIERS Final Report, Washington, DC: Population Council. 
APPENDIX

Systematic Screening Instrument 


\section{LISTA DE VERIFICACIÓN PARA LA OFERTA INTEGRAL DE SERVICIOS DE SALUD SEXUAL Y REPRODUCTIVA}

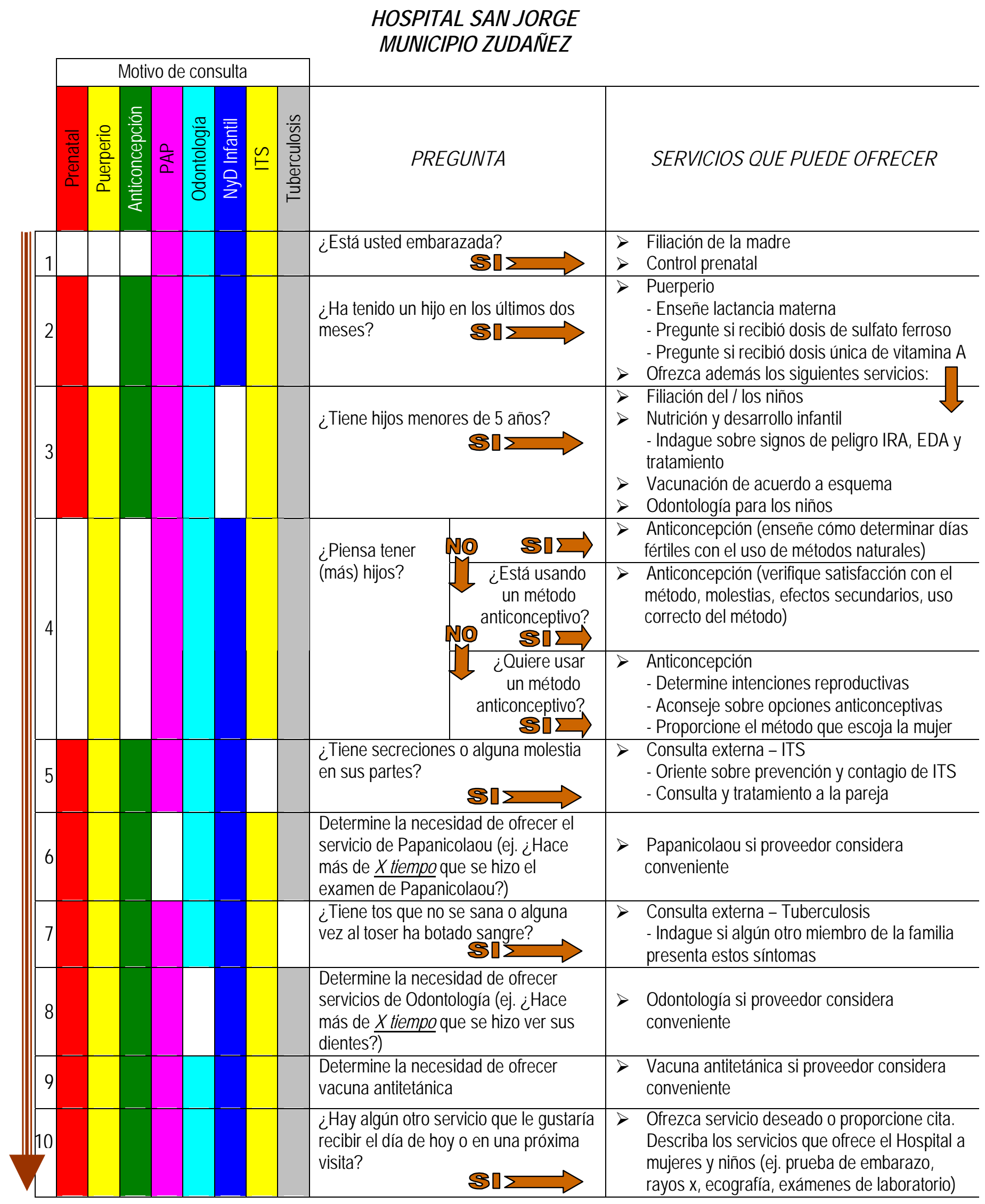




\section{INSTRUCCIONES}

Esta lista de verificación se utiliza para ofrecer a la mujer servicios adicionales a los que ella vino a buscar. Su aplicación no toma más de cinco minutos. Por ejemplo, si la mujer vino por una consulta prenatal (color rojo), además de recibir este servicio, el proveedor le ofrecerá servicios de puerperio (pregunta \#2), nutrición y desarrollo infantil (pregunta \#3), ITS (pregunta \#5), se indagará la necesidad de ofrecerle servicios de Papanicolaou (pregunta \#6), tuberculosis (pregunta \#7), odontología (pregunta \#8), vacuna antitetánica (pregunta \#9), y además el proveedor describirá los servicios que ofrece el hospital (pregunta \#10.).

Estos son los pasos que debe seguir el proveedor para aplicar esta lista:

1. Pregunte a la mujer su edad. Aplique esta lista solamente si ella tiene entre 15 y 49 años, o viene acompañando a un niño menor de 5 años.

2. Pregunte a la mujer cuál es el motivo de su consulta.

3. Cada columna de color lleva el nombre de un motivo de consulta. De acuerdo a su respuesta, formule las preguntas en orden de arriba a abajo según el código de colores. En el caso de que la mujer haya venido por un servicio diferente al del código de colores, (ej. consulta externa, paludismo, chagas, insuficiencias cardiacas, etc.) formule todas las preguntas de arriba abajo desde la 1 hasta la 10.

a. Formule la pregunta que corresponda según el color del motivo de consulta de la mujer. Si la respuesta de la mujer es "SI", ofrezca los servicios que se describen en la casilla a la derecha de la pregunta. Si la respuesta es "NO", continúe con la siguiente pregunta hacia abajo que corresponda al color del motivo de consulta de la mujer. No formule las preguntas que tienen casillas en blanco.

b. Una vez ofrecidos y detectados todos los servicios que la mujer necesita, anote en el Cupón de Servicios a Recibir los servicios que a la mujer le interesa recibir. Entregue este cupón a la mujer.

c. Derivar a la mujer inmediatamente al consultorio para que obtenga el servicio por el que vino al hospital. Los servicios detectados con la lista se le proporcionarán a la mujer después de que ella haya recibido el servicio por el que originalmente vino al hospital. 